with them (MourT's Relation, p. 55 [Dexter's edition]). William Wood (New England's Prospect, part ii. chap. xvii. p. 101) speaks of them as made of this material: so does the Rev. Francis Higginson ("New England's Plantation," in YounG's Chronicles of Massachusetts, p. 257).

Undoubtedly the Indians found it easier to cut up brass kettles for this purpose than to pound out with their stone hammers pieces of native copper. This they were in the habit of doing, according to Brereton ("Brief and True Relation of the Discovery of the North Part of Virginia," in Collections of Massachusetts Historical Society [3d series], vol. viii. p. 91).

Boston, Jan. 13. Henry W. Haynes.

\section{Meteorology and Mathematics.}

At a time when the tide of meteorological controversy in your columns runs high and the general outcry is for revision of the old theories, - all apparently because Dr. Hann last spring made some, erroneous deductions from observations in the Alps, which has not convinced anybody (vide Hazen), - you may permit me to add my small share to the general conflagration, out of the ashes of which the true Phœnix may some day be expected to rise in all its glory.

What I here wish to sacrifice on the altar of truth is the so-called mathematical treatment of the circulation of the atmosphere; and I take occasion from a letter by William Ferrel in your issue of Jan. 2, wherein the writer complains that Dr. Hann has never attempted to show that his results have been deduced from erroneous principles or processes.

I am not aware that any mathematician has ever attempted to show, on rational mechanical principles, what would be the motion of a body of air moving over the surface of a rotating globe,not over the free and empty surface, but on the bottom of the air universally enveloping and rotating with this globe, being part and parcel of this air itself,- - but I think it can be shown, by looking ever so little into the true nature of this subject, that the problem is far more complicated than Professor Ferrel seems to imagine.

As the speed wherewith places at different latitudes on the earth's surface rotate differ in proportion to their distances from the axis, so it is concluded by Ferrel and others that a particle of air is deflected towards the east when moving towards the poles, and towards the west when moving towards the equator.

In proportion, however, as the speed of rotation of the particle of air changes while it moves from latitude to latitude, so also the centrifugal force to which it is exposed changes; and therefore, if a change in the former should have the effect of deflecting a current of surface air laterally, so also the effect of the latter must be to deflect the current in a vertical direction. The result hereof is that all pole-bound currents should appear as upper currents, and the surface wind should always be directed more or less towards the equator, and never in the opposite direction. This, however, does not agree with observations. There is a continuous current of surface air round the border of any anticyclone, while in strict consequence of Professor Ferrel's theory we should only expect to find this current round one-half the circumference of the high pressure, the other half being deflected into an upper current.

According to the way the writer was taught applied mathematics (a discipline, by the way, incomparably more difficult to master than mathematics itself), it is not admissible to pick out one of the forces acting upon a body in motion, and ignore another of equal importance, simply because it does not suit our purposes.

In a paper, "On the Cause of Trade-Winds," read before the American Society of Civil Engineers Dec. 18, 1889 (see "Transactions," vol. xxiii. August, 1890), the writer allowed himself to suggest how the gyratory motion of the surface air might be accounted for independently of a supposed effect of the earth's rotation, which theory, as we have just seen, doesn't bear closer inspection; and one of America's most eminent engineers, Mr. Charles Macdonald, got up at the meeting, and declared the explanation given the only rational one he had ever heard, and well worth the most careful study. I therefore beg to call the reader's attention to the contents of this paper; and, by comparing my diagrams with the isobaric charts over the North Atlantic for the autumn of 1889 , he may see the reason why Dr. Hann found the temperature of the anticyclonic air in the Alps so exceptionally high. Franz A. Velschow, C.E.

Brooklyn, Jan. 7.

\section{The Education of the Deaf.}

SPOKEN language is the product of the mind enjoined with the enjoyment of all the senses. Its acquisition is facilitated through the sense of hearing, but the latter is not indispensable to it; and to its reproduction by the deaf (without its musical intonation) a normal throat and mouth are requisite. Dr. Gillett says, "This [intelligence] the deaf-mute has perfectly" (Science, Dec. 26, p. 355). As most of the deaf possess these requirements, the question that now arises is this: "Is it expedient to invent an artificial sign-language, which of course presupposes articulate speech, in order to impart the latter to the deaf?" Emphatically, no. The oral schools now in existence in this country prove this fact beyond the shadow of a doubt. One of Dr. Gillett's objections is this: "For, while he [the deaf] may utter distinct articulate sounds for others to receive, he cannot receive them himself, and is consequently thrown back upon the visible movements of the superficial parts of the organs of voice, which are chiefly the lips" (Science, Dec. 26, p. 357). The deaf will read from the lipsmouth readily when spoken to without voice, that is, mutely and it is a phenomenon that they are enabled to recognize even the distinction between being addressed audibly and mutely. They will often converse mutely with each other in the schoolroom, when desirous of not being overheard by their teacher. Lately one of my patients happened to be a Chinaman. On inquiring of him what he uses at his meals, - a fork and a knife, or chop-sticks, - he said that at home he uses the latter, but when eating at a restaurant he uses the former. Early education and impressions are lasting. The same is applicable to those mutes who are educated by the combined system, where an artificial sign-language forms the basis of instruction. When a mute educated by that system meets a deaf-mute who was taught by the oral system, the former will naturally address the latter by signs. To start the conversation, the first question perhaps will be, "Do you know Mr. P- $t$ ?" The sign for " Mr. P- $t$ " is this: closing the thumb and all the fingers except the forefinger, with which he taps himself at the temple. The other repeats the sign for "P-t," shakes his head, and indicates by expressions that he does not know what this sign means; then the former spells with his fingers the words "P-t, teacher;" and such conversations may occur so often that the one learns the meaning of signs from the other. The deaf educated by the oral system become so ambitious that they make efforts when in a small circle of society, by constant watchfulness, to follow the connection of the conversation, and try to hide their infirmity. They are even ashamed to use signs. I would gladly go extensively into the details of Dr. Gillett's article on the education of the deaf, but the pressure of professional duties will not permit me to devote the time necessary. I would like, though, to direct Dr. Gillett's attention to Hon. Gardiner G. Hubbard's article in Science of Dec. 19, to which I have to make the one exception only, that the first oral school in this country was established in this city, and was in operation in the fall of 1864 at No. 427 (old number 415) Eighth Avenue, consisting of two boarding and three day pupils.

New York, Jan. 8.

\section{BOOK-REVIEWS}

The Science of Fairy Tales. By Edwin Sidney HaRtLand. New York, Scribner \& Welford. $12^{\circ}$. $\$ 1.25$.

THIs volume is the latest issue in the Contemporary Science Series, and may be described as an attempt to group and classify the various stories of Celtic and Teutonic origin relating to elves and fairies, with illustrations from the stories of other nations. Mr. Hartland opens his work with a few remarks on savage ideas, 